\title{
EVALUASI KINERJA AQUEOUS AMMONIA PLANT (STUDI DESKRIPTIF DI PABRIK PUPUK)
}

\author{
Nur Aida Amalia, Nurul Syefira Fatayatunnajmah, Bintang Iwhan Moehady \\ Jurusan Teknik Kimia, Politeknik Negeri Bandung, Bandung 40012 \\ Email: nuraidamalia20@gmail.com, syefira41@gmail.com, bintang@polban.ac.id
}

\begin{abstract}
ABSTRAK
Di Indonesian terdapat pabrik pupuk yang memproduksi aqueous ammonia dengan konsentrasi 25-30\%. Pembuatan aqueous ammonia dilakukan dengan cara mencampurkan amonia anhidrat dengan air. Kendala yang dihadapi ialah adanya aqueous ammonia yang hilang sehingga kebutuhan amonia anhidrat sebagai umpan menjadi lebih banyak. Hilangnya aqueous ammonia terjadi karena kondisi operasi proses pembuatan aqueous ammonia belum optimal. Penelitian ini bertujuan untuk menentukan suhu dan tekanan optimum pada proses pembuatan aqueous ammonia $25-30 \%$ dengan fasa uap yang terbentuk kurang dari 13\%. Angka tersebut merupakan batas maksimum $\%$ amonia hilang yang diperbolehkan berdasarkan data aktual yang diperoleh dari lapangan. Proses optimasi menggunakan perangkat lunak HYSYS. Proses simulasi mengikuti urutan proses yang terjadi di industri yang terdiri dari Mixer, Shell and Tube Heat Exchanger (STHE), dan Tangki Penyimpanan. Simulasi diawali dengan menentukan variasi tekanan, suhu, dan fraksi aqueous ammonia untuk optimasi kondisi operasi di tangki penyimpanan. Hasil penelitian menunjukkan bahwa kondisi operasi optimum di Tangki Penyimpanan terjadi pada suhu $30-45^{\circ} \mathrm{C}$, tekanan $1,2-2 \mathrm{~kg} / \mathrm{cm} 2$ dan konsentrasi $26-30 \%$. Optimasi kemudian dilanjutkan ke Mixer dan STHE yang mengacu pada kondisi operasi tangki penyimpanan. Suhu optimum keluaran Mixer adalah pada $57-58^{\circ} \mathrm{C}$. Kondisi optimum STHE adalah pada rentang suhu masukan $\quad 57-58^{\circ} \mathrm{C}$ dan keluaran $43-45^{\circ} \mathrm{C}$. Perbedaan kondisi antara hasil simulasi dengan data aktual adalah pada laju alir umpan amonia anhidrat dan air (kebutuhan amonia berkurang 24,9-54,9 kg/h dari kebutuhan amonia aktual), suhu keluaran STHE $\left(2^{\circ} \mathrm{C}\right.$ lebih kecil dari data aktual), dan tekanan optimum pada Tangki Penyimpanan lebih besar dari tekanan aktual $(1,5 \mathrm{~kg} / \mathrm{cm} 2$ terhadap $2 \mathrm{~kg} / \mathrm{cm} 2)$.
\end{abstract}

Kata Kunci. Aqueous ammonia, optimasi, kondisi operasi, \% amonia hilang.

\section{PENDAHULUAN}

Pabrik pupuk pada penelitian ini memproduksi pupuk urea sebagai produk utama dan amonia anhidrat sebagai produk samping. Amonia anhidrat yang diproduksi ada dua jenis, yakni Ammonia Hot Product dan Ammonia Cold Product. Perbedaan dari kedua produk tersebut adalah konsentrasi amonia, kandungan air serta kondisi suhu dan tekanan.

Ammonia Cold Product memiliki konsentrasi yang tinggi, sedangkan permintaan dari pelaku industri farmasi dan kosmetik menginginkan konsentrasi amonia $25-30 \%$. Hal ini mendorong salah satu pabrik pupuk di Indonesia membuat produk amonia cair dengan konsentrasi 25-30\%. Pembuatan aqueous ammonia dilakukan dengan mencampurkan ammonia anhidrat dan air demineralisasi. Namun, saat ini kondisi operasi di Aqueous Ammonia Plant belum optimal sehingga mengakibatkan ammonia cair yang dihasilkan mudah menguap. Adanya amonia yang menguap menyebabkan kebutuhan amonia anhidrat menjadi berlebih.

Aqueous Ammonia Plant terdiri dari Mixer, Shell and Tube Heat exchanger (STHE) dan Tangki Penyimpanan. Proses pencampuran dalam mixer berada pada tekanan $3,15 \mathrm{~kg} / \mathrm{cm} 2$ dengan laju alir ammonia anhidrat dan air masing-masing 250 $\mathrm{kg} / \mathrm{h}$ dan $750 \mathrm{~kg} / \mathrm{h}$. Proses pendinginan dalam STHE dapat menurunkan suhu hingga $6^{\circ} \mathrm{C}$, 
proses penyimpanan dalam tangki berada pada tekanan $1-1,5 \mathrm{~kg} / \mathrm{cm} 2$ dan suhu $30-50^{\circ} \mathrm{C}$. Kondisi operasi di Aqueous Ammonia Plant saat ini dapat menyebabkan 13\% amonia dari total umpan menjadi uap sehingga perlu dilakukan perbaikan pada kondisi operasi di mixer, STHE, dan tangki penyimpanan.

Tujuan pada penelitian ini adalah mendapatkan suhu dan tekanan optimum pada proses pembuatan aqueous ammonia untuk menghasilkan konsentrasi aqueous ammonia 25-30\% dengan fasa uap yang terbentuk kurang dari $13 \%$ amonia yang diumpankan. Manfaat penelitian ini adalah membantu perusahaan dalam menentukan kondisi operasi optimum pada proses pembuatan aqueous ammonia 25-30\% sehingga dapat mengurangi kerugian yang ditimbulkan.

\section{BAHAN DAN METODE}

Metode penelitian yang digunakan pada proses optimasi pembuatan aqueous ammonia merupakan metode simulasi dengan menggunakan software HYSYS 7.3. Proses optimasi diawali dengan melakukan validasi simulasi HYSYS dengan data aktual yang diperoleh dari lapangan. Validasi ini bertujuan untuk menguji simulasi HYSYS agar mempunyai kondisi yang sama dengan aqueous ammonia plant. Hasil simulasi kemudian dibandingkan dengan data aktual, apabila variabel yang divalidasi mendapatkan \%error kurang dari $10 \%$ maka data tersebut dikatakan valid.

Tahap selanjutnya adalah melakukan optimasi tangki penyimpanan menggunakan simulasi HYSYS dengan menentukan variasi suhu, tekanan, dan konsentrasi ammonia yang masuk ke dalam tangki penyimpanan. Hasil dari simulasi tangki penyimpanan kemudian dihitung $\%$ kehilangan amonia. $\%$ kehilangan amonia yang kurang dari 13\% diambil sebagai kondisi operasi optimum. Kondisi operasi optimum di tangki penyimpanan kemudian digunakan untuk menentukan kondisi operasi optimum di Mixer dan STHE.
Simulasi mixer dan STHE dimulai dari mixer dimana konsentrasi aqueous ammonia yang terbentuk menjadi variabel yang divariasikan dengan kondisi umpan sama dengan keadaaan aktual. Simulasi kemudian dilanjut ke STHE untuk mendapatkan suhu keluaran STHE. Setelah didapat semua kondisi operasi di Aqueous Ammonia Plant, data kemudian diolah untuk penyusunan analisis hasil, pembahasan, serta kesimpulan dan saran.

\section{HASIL DAN PEMBAHASAN}

\section{Validasi Simulasi Hysys dengan Data Aktual}

Hasil validasi simulasi hysys dengan data aktual disajikan dalam Tabel 1.

Tabel 1. Validasi Simulasi HYSYS dengan Data Aktual

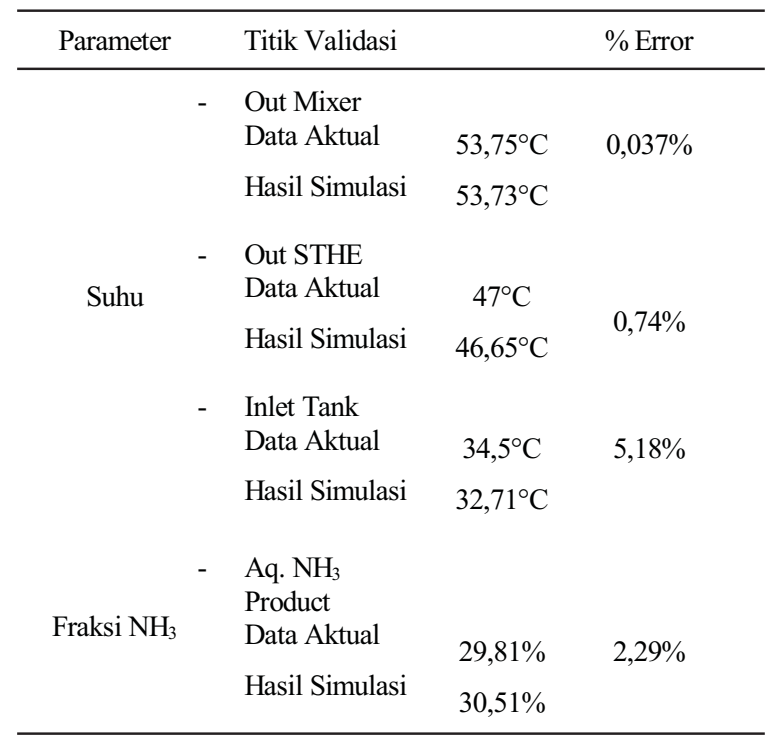

Data aktual tersebut merupakan kondisi operasi rata-rata yang diambil setiap satu jam pada saat proses pembuatan aqueous ammonia berlangsung (6-8 jam). Hasil validasi simulasi HYSYS dengan data aktual memperoleh \%error kurang dari 10\% sehingga simulasi tersebut dapat dilakukan untuk mengoptimasi proses pembuatan aqueous ammonia. 


\section{Simulasi Optimasi Aqueous Ammonia} Plant

Simulasi optimasi aqueous ammonia plant dimulai dengan mengevaluasi tangki penyimpanan. Evaluasi tangki penyimpanan dilakukan dengan mencari tahu \% kehilangan amonia pada variasi tekanan $(\mathrm{P})$, suhu $(\mathrm{T})$, dan konsentrasi.

Berdasarkan variasi konsentrasi yang telah ditentukan, data yang diperoleh menunjukkan bahwa semakin tinggi fraksi aqueous ammonia yang masuk ke dalam tangki penyimpanan akan semakin banyak amonia yang hilang atau teruapkan. Amonia yang hilang disebabkan karena tekanan uap parsial amonia dalam aqueous ammonia semakin tinggi sehingga memudahkan amonia untuk menguap.

Batasan maksimal fraksi aqueous ammonia yang memenuhi syarat pada $\mathrm{P}$ dan $\mathrm{T}$ tetap ditunjukkan pada Tabel 2.

Tabel.2: Batas Konsentrasi Maksimum di Tangki Penyimpanan yang Memenuhi Syarat

\begin{tabular}{ccc}
\hline $\mathrm{P}$ & $\mathrm{T}$ & \\
$\left(\mathrm{kg} / \mathrm{cm}^{2}\right)$ & $\left({ }^{\circ} \mathrm{C}\right)$ & Batas konsentrasi maksimal $(\%)$ \\
\hline 1,2 & 30 & 28,4 \\
1,4 & 30 & $>30$ \\
1,4 & 35 & 28 \\
1,6 & 30 & $>30$ \\
1,6 & 35 & 30 \\
1,6 & 40 & 27,45 \\
1,8 & 30 & $>30$ \\
1,8 & 35 & $>30$ \\
1,8 & 40 & 29,3 \\
1,8 & 45 & 26,7 \\
2 & 30 & $>30$ \\
2 & 35 & $>30$ \\
2 & 40 & $>30$ \\
2 & 45 & 28,3 \\
\hline & & \\
\hline & 35 & \\
\hline & & 30 \\
\hline
\end{tabular}

Berdasarkan variasi tekanan yang telah ditentukan, diperoleh hasil bahwa semakin tinggi tekanan pada tangki penyimpanan \% amonia yang hilang akan semakin kecil. Hal ini disebabkan karena tekanan yang tinggi akan menaikkan titik didih aqueous ammonia sehingga kemungkinan untuk teruapkan menjadi lebih kecil. Adapun batas minimum tekanan yang memenuhi syarat untuk menghasilkan \% amonia hilang kurang dari 13\% ditunjukkan pada Tabel 3 .

Tabel. 3: Batas Tekanan Minimum di Tangki Penyimpanan yang Memenuhi Syarat

\begin{tabular}{ccc}
\hline $\mathrm{T}\left({ }^{\circ} \mathrm{C}\right)$ & Konsentrasi $(\%)$ & $\mathrm{P} \min \left(\mathrm{kg} / \mathrm{cm}^{2}\right)$ \\
\hline 30 & 26 & $<1,2$ \\
30 & 27 & $<1,2$ \\
30 & 28 & $<1,2$ \\
30 & 29 & 1,25 \\
30 & 30 & 1,33 \\
35 & 26 & 1,22 \\
35 & 27 & 1,31 \\
35 & 28 & 1,39 \\
35 & 29 & 1,49 \\
35 & 30 & 1,58 \\
40 & 26 & 1,45 \\
40 & 27 & 1,56 \\
40 & 28 & 1,66 \\
40 & 29 & 1,78 \\
40 & 30 & 1,89 \\
45 & 26 & 1,72 \\
45 & 27 & 1,84 \\
45 & 28 & 1,96 \\
\hline & &
\end{tabular}

Batas tekanan minimum tersebut diperkuat dengan data pada Tabel 4. yang diambil berdasarkan enthalpy-concentration diagram for aqueous ammonia.

Tabel 4: Titik Didih Aqueous Ammonia pada Suhu dan Konsentrasi Tertentu

\begin{tabular}{ccc}
\hline $\begin{array}{c}\text { Konsentrasi } \\
(\%)\end{array}$ & $\begin{array}{c}\text { Suhu } \\
\left({ }^{\circ} \mathrm{C}\right)\end{array}$ & Boiling Point Pressure $\left(\mathrm{kg} / \mathrm{cm}^{2}\right)$ \\
\hline 26 & 30 & 0,82 \\
27 & 35 & 1,02 \\
28 & 40 & 1,43 \\
29 & 45 & 1,83 \\
30 & 50 & 2,24 \\
\hline
\end{tabular}


Aqueous ammonia yang memiliki konsentrasi $26 \%$ dan suhu $30 \mathrm{oC}$ mendidih pada tekanan $0,82 \mathrm{~kg} / \mathrm{cm} 2$. Pada saat mendidih, gas ammonia yang menguap akan lebih banyak dari 13\%. Oleh karena itu, diperlukan batas minimum tekanan di tangki penyimpanan agar amonia tidak mudah menguap. Batas tekanan minimum tersebut harus lebih besar dari pada tekanan pada saat aqueous ammonia mendidih.

Penguapan ammonia dapat dicegah dengan cara tekanan pada proses pembuatan aqueous ammonia diperbesar. Adapun batas minimum pada Tabel 3 dapat digunakan untuk memproduksi aqueous ammonia dengan \% kehilangan ammonia di bawah $13 \%$, apabila tekanannya diturunkan maka akan memperoleh \% amonia hilang yang lebih banyak.

Berdasarkan variasi suhu yang telah ditentukan, didapat hasil bahwa semakin tinggi suhu di tangki penyimpanan \% kehilangan ammonia semakin banyak. Semakin tinggi suhu pada tangki penyimpanan menyebabkan aqueous ammonia mencapai titik didihnya dan teruapkan.

Tabel. 5: Batas Suhu Maksimum di Tangki Penyimpanan yang Memenuhi Syarat

\begin{tabular}{ccc}
\hline $\begin{array}{c}\mathrm{P} \\
\left(\mathrm{kg} / \mathrm{cm}^{2}\right)\end{array}$ & $\begin{array}{c}\text { Konsentrasi } \\
(\%)\end{array}$ & $\mathrm{T}$ maks $\left({ }^{\circ} \mathrm{C}\right)$ \\
\hline 26 & 1,2 & 34,5 \\
26 & 1,4 & 39 \\
26 & 1,6 & 43 \\
26 & 1,8 & 46,5 \\
26 & 2 & 49,8 \\
27 & 1,2 & 33 \\
27 & 1,4 & 37 \\
27 & 1,6 & 41 \\
27 & 1,8 & 44,5 \\
27 & 2 & 48 \\
28 & 1,2 & 31 \\
28 & 1,4 & 35 \\
28 & 1,6 & 39 \\
28 & 1,8 & 42,5 \\
28 & 2 & 45,5 \\
29 & 1,4 & 33,5 \\
29 & 1,6 & 37 \\
29 & 1,8 & 40,5 \\
29 & 2 & 44 \\
30 & 1,4 & 32,5 \\
30 & 1,6 & 35 \\
30 & 1,8 & 38,5 \\
30 & 2 & 42 \\
\hline
\end{tabular}

Tabel 5 memerlihatkan suhu yang bisa digunakan pada proses pembuatan aqueous ammonia agar menghasilkan \% amonia hilang kurang dari 13\%. Berdasarkan enthalpy-concentration diagram for aqueous ammonia sehingga diperoleh data pada Tabel 6.

Tabel 6: Titik Didih Aqueous ammonia pada Tekanan dan Konsentrasi Tertentu

\begin{tabular}{ccc}
\hline $\begin{array}{c}\text { Konsentrasi } \\
(\%)\end{array}$ & $\begin{array}{c}\text { Tekanan } \\
\left(\mathrm{kg} / \mathrm{cm}^{2}\right)\end{array}$ & $\begin{array}{c}\text { Boiling Point } \\
\text { Temperature }\left({ }^{\circ} \mathrm{C}\right)\end{array}$ \\
\hline 26 & 1,2 & 38 \\
27 & 1,4 & 41 \\
28 & 1,6 & 43 \\
29 & 1,8 & 45 \\
30 & 2 & 46 \\
\hline
\end{tabular}

Titik didih aqueous ammonia pada konsentrasi dan tekanan tertentu memiliki nilai yang berbeda, sehingga batas maksimum suhu yang digunakan pada setiap kondisi pun berbeda. Suhu $50^{\circ} \mathrm{C}$ tidak dianjurkan untuk digunakan pada proses pembuatan aqueous ammonia. Berdasarkan Tabel 6, suhu tersebut melebihi titik didih aqueous ammonia pada konsentrasi dan tekanan yang divariasikan.

Data yang diperoleh dari hasil simulasi dan perhitungan berdasarkan data variasi kemudian diambil beberapa kondisi operasi dilihat dari \% amonia hilang yang kurang dari 13\%. Angka tersebut ditentukan dari $\%$ amonia hilang berdasarkan data actual. Hasil simulasi dan perhitungan disajikan pada Gambar 7.

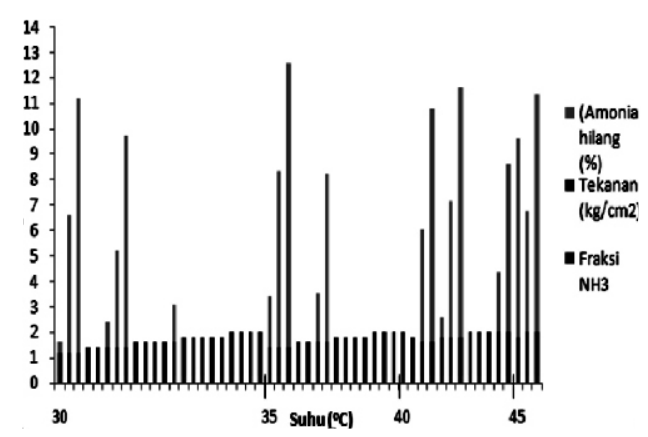

Gambar 7. Kurva Hasil Simulasi dan Perhitungan 
Gambar 7 menunjukkan bahwa suhu $30^{\circ} \mathrm{C}$ menghasilkan \% amonia hilang terkecil pada berbagai tekanan dan konsentrasi. Semakin tinggi suhu tangki penyimpanan, semakin sedikit variasi tekanan dan konsentrasi yang dapat digunakan untuk menghasilkan \% kehilangan amonia dibawah $13 \%$.

Hasil yang diperoleh dari evaluasi tangki penyimpanan kemudian dimasukkan ke dalam simulasi HYSYS untuk melakukan evaluasi pada mixer dan STHE.

Analisis Pengaruh Suhu, Tekanan, dan Konsentrasi terhadap \% Kehilangan Amonia

Analisis menggunakan software Polymath 6.0 yang bertujuan untuk mengetahui seberapa besar pengaruh suhu, tekanan, dan konsentrasi terhadap \% amonia hilang. Hasil analisa memperoleh model matematika sebagai berikut :

$\%$ ammonia hilang $=-82,39521+(-$ $29,60774 * \mathrm{P})+(1,650552 * \mathrm{~T})+($ $2,905804 * x)$

Keterangan :

$\mathrm{P}=$ tekanan $(\mathrm{kg} / \mathrm{cm} 2)$

$\mathrm{T}=\operatorname{suhu}(\mathrm{oC})$

$\mathrm{x}=$ konsentrasi amonia $(\%)$

Analisa tersebut menghasilkan koefisien determinasi (R2) sebesar 0,9340. Nilai R2 menunjukkan bahwa 93,40\% tekanan, suhu, dan konsentrasi berpengaruh terhadap perubahan \% amonia hilang. Sedangkan sisanya $6,6 \%$ perubahan $\%$ ammonia hilang dipengaruhi oleh variabel yang tidak diketahui.

\section{Penentuan Kondisi Operasi Optimum pada Mixer dan Shell and Tube Heat Exchanger (STHE)}

Hal pertama yang dilakukan untuk mendapatkan kondisi operasi optimum pada mixer dan STHE adalah membuat simulasi Aqueous Ammonia Plant pada Software
HYSYS. Satu buah Mixer, pipa dengan ukuran 1,5" sch 40 dengan total panjang 1,12 $\mathrm{m}$, satu buah STHE, pipa dengan ukuran 1,5" sch 40 dengan total panjang $6,78 \mathrm{~m}$, dan tangki penyimpanan digunakan sebagai acuan simulasi.

Pada simulasi ini, variabel yang di variasikan adalah konsentrasi dari aqueous ammonia outlet Mixer. Laju alir aqueous ammonia outlet Mixer dibuat konstan yaitu $750 \mathrm{~kg} / \mathrm{h}$ sesuai data aktual. Selain itu, kondisi operasi dan konsentrasi dari inlet mixer juga dibuat konstan. Bahan baku amonia anhidrat memiliki konsentrasi 99,95\% dengan suhu $20 \mathrm{oC}$ dan tekanan $22 \mathrm{~kg} / \mathrm{cm} 2$ sedangkan air memiliki suhu 30oC dan tekanan 4,6 kg/cm2 . Konsentrasi aqueous ammonia outlet mixer yang dimodifikasi mengacu pada kondisi operasi tangki penyimpanan yang telah diperoleh. Hasil yang diperoleh berupa laju alir masuk amonia anhidrat dan air, serta kondisi operasi pada STHE.

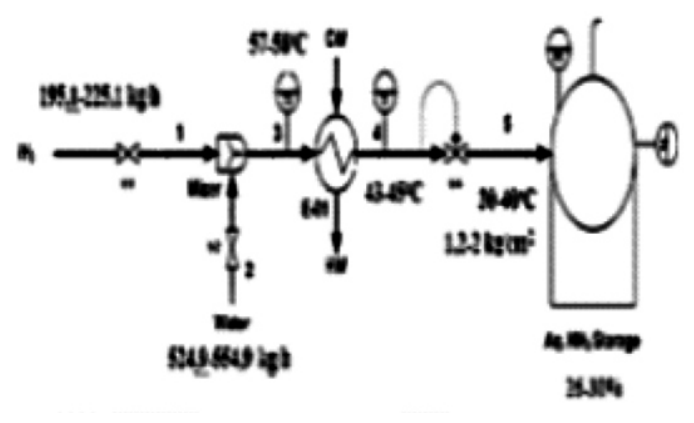

Gambar 8. Hasil Evaluasi Aqueous Ammonia Plant

Hasil simulasi menunjukkan laju alir amonia anhidrat yang diperlukan untuk menghasilkan konsentrasi $26-30 \%$ adalah $195,1-225,1 \mathrm{~kg} / \mathrm{h}$. Kondisi operasi di STHE terdiri dari suhu masuk berkisar antara 57$58 \mathrm{oC}$ dan suhu keluar STHE antara 43-45oC, sedangkan suhu masuk tangki 30-40oC sesuai dengan data variasi. Hasil simulasi ditunjukkan pada Gambar 8.

Kondisi operasi actual di outlet mixer adalah 42-58oC, outlet STHE 45-52oC, serta inlet tangki penyimpanan 26-38oC dan 
$1 \mathrm{~kg} / \mathrm{cm} 2$.

Laju alir umpan amonia anhidrat dan air adalah $250 \mathrm{~kg} / \mathrm{h}$ dan $500 \mathrm{~kg} / \mathrm{h}$. Kondisi tersebut menghasilkan $29,81 \%$ aqueous ammonia dengan 13\% amonia hilang. Perbedaan antara data aktual dan hasil simulasi terletak pada laju alir umpan amonia anhidrat dan air, dimana pada hasil simulasi kuantitas laju alir amonia anhidrat yang diperlukan lebih sedikit, tetapi laju alir air demin lebih banyak. Selain itu, perbedaan juga terletak pada suhu keluar STHE. Hasil simulasi berada pada 43-45oC sedangkan data aktual berada pada rentang $45-52 \mathrm{oC}$. Hal ini menunjukkan bahwa suhu keluaran STHE harus diperkecil, salah satu cara yang bisa dilakukan ialah dengan memperbesar laju alir cooling water yang masuk ke dalam STHE. Tekanan aliran masuk tangki penyimpanan pada data aktual adalah $1-1,5 \mathrm{~kg} / \mathrm{cm} 2$ sedangkan hasil simulasi yakni pada rentang $1,2-2 \mathrm{~kg} / \mathrm{cm} 2$. Disamping itu, untuk suhu

\section{DAFTAR RUJUKAN}

Anonim1.1997.Osmonics Pure Water Handbook, 2nd edition, USA: Osmonics, Inc. Minnetoka.

Anonim2.2010. Aqua Ammonia Technical Data Manual. (Online). http://www.airgasspecialtyp roducts.com/technicalLibrary/aquaA mmoni aTechManual.aspx.(Diakses pada 19 Maret 2015)

Anonim3.2015. Arsip Process Engineering PT. Pupuk Kujang 1A, Cikampek: PT. Pupuk Kujang. 2015. (tidak diterbitkan)

Anonim4.2015.Arsip Unit Amonia 1A. Cikampek: PT. Pupuk Kujang. 2015. (tidak diterbitkan)

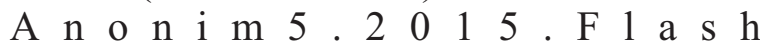
Distillation.(Online).http://kkft.bme. $\mathrm{hu} /$ sites/default/files/flash distillatin. pdf.(Diakses pada 19 Maret 2015) Anonim6.2015.Material Safety Data SheetAmmonia. aktual pada outlet mixer dan aliran masuk tangki penyimpanan telah sesuai dengan rentang yang diperoleh dari hasil simulasi.

Selain itu, kondisi optimum tangki penyimpanan berada pada rentang suhu 3040oC sedangkan suhu lingkungan di pabrik mencapai 33oC sehingga dianjurkan tangki penyimpanan menggunakan isolasi agar suhu lingkungan tidak memengaruhi proses pembuatan aqueous ammonia.

\section{SIMPULAN}

Hasil penelitian evaluasi kinerja aqueous ammonia plant pada proses pembuatan aqueous ammonia 25-30\%, diperoleh kondisi operasi optimum hasil simulasi, yaitu suhu keluaran mixer antara 57$58 \mathrm{oC}$, suhu keluar STHE berkisar 43-45oC, sedangkan suhu masuk tangki 30-40oC dan tekanan masuk tangki $1,2-2 \mathrm{~kg} / \mathrm{cm} 2$.

Anonim6.2015.Material Safety Data Sheet A $m \quad m \quad o \quad n \quad r \quad a$. (Online).http://www.airgasspecialtypr oducts.com/Libraries/SDS/Anhydrou s_Ammonia_SDS.sflb.ashx.(Diakses pada 4Agustus 2015)

Appl, M.1999. Ammonia : Principles and Industrial Practice, Wiley-VCH, Weinheim,pp. 221-235.

Ekasari, Silvia Rahmi. 2013.Penyisihan Amonia dari Air Limbah menggunakan Gabungan Proses Membran dan Oksidasi Lanjut dalam Reaktor Hibrida Ozon-Plasma menggunakan larutan penyerap Asam Sulfat. Depok : Fakultas Teknik Universitas Indonesia.

Geankoplis, Christie John.2003. Transport Process and Separation Process Principles 4th Edition. New Jersey: Pearson Education, Inc.

Sidiq, Agus Noor.2008. Pencampuran A $m$ m o n i a - W a $t$ e $r$. lib.ui.ac.id/file?file $=$ digital $/ 126604-$ $\begin{array}{llllllll}\mathrm{r} & 0 & 2 & 0 & 8 & 0 & 2 & -\end{array}$ 
Analisis\%20energi...pdf.(Diakses pada 25 Mei 2015)

11]. Terra Centre.2011.Material Safety Data
Sheet of Aqua Material (19-30\%). Sioux City, Iowa: Terra a CF Industries Compan 